\title{
Strategic Transparency and Informed Trading: Will Capital Market Integration Force Convergence of Corporate Governance?
}

\author{
Enrico C. Perotti and Ernst-Ludwig von Thadden*
}

\begin{abstract}
Dominant investors can influence the publicly available information about firms by affecting the cost of information collection. Under strategic competition, transparency results in higher variability of profits and output. Thus, lenders prefer less transparency, since this protects firms when in a weak competitive position, while equity holders prefer more. Market interaction creates strategic complementarity in gathering information on competing firms, thus entry by transparent competitors will improve price informativeness. Moreover, as the return to information gathering increases with liquidity, increasing global trading may undermine the ability of bank control to keep firms opaque.
\end{abstract}

\section{Introduction}

This paper seeks to contribute to the debate on the convergence of corporate governance structures across countries. A central difference usually identified among governance systems is the relative degree of influence of equity market investors vs. other institutions, which may be large lenders (banks) or large inside equity holders (usually family-controlled holding companies). Yet, while there are sharply different views on their comparative efficiency, there is to date little theoretical work on the process of competing vs. converging governance forms.

The literature on legal origin has taken the view that the structure of financial systems is defined by historical legal tradition and therefore is nearly immutable (La Porta, Lopez-de-Silanes, Shleifer, and Vishny (1997), (1998)). This view has been challenged by other authors who argue that financing and governance systems change over time, responding to the evolution of domestic political circumstances (Rajan and Zingales (2001), Biais and Perotti (2002)). In the legal literature, some authors see convergence to the Anglo-Saxon model as a near certainty

\footnotetext{
*Perotti, enrico@fee.uva.nl, University of Amsterdam, Department of Financial Management, Roeterstraat 11, Amsterdam, WB 1018, Netherlands and CEPR; von Thadden, elu.vonthadden@ hec.unil.ch, Université de Lausanne, Lausanne, CH-1015, Switzerland, FAME, and CEPR. We thank Sudipto Bhattacharya, Martin Hellwig, Bengt Holmström, Colin Mayer, Jean Tirole, and Xavier Vives as well as participants in seminars, at two CEPR conferences in Tolouse and INSEAD, and participants at the Corporate Governance conference in Tilburg for comments. Special thanks to Paul Malatesta (the editor) for many useful suggestions. von Thadden thanks the Swiss National Competence Center in Research (FinRisk) for support. All views expressed in this paper are the authors' own.
} 
(Hansmann and Kraakman (2003)). Others (Bebchuk and Roe (1999)) have suggested that path dependence will persist, leaving national systems of governance pursuing parallel paths. Finally, many authors see competition in legislation as a powerful tool for convergence (Easterbrook and Fischel (1991)).

Much attention has been dedicated to comparative information efficiency of shareholder control over delegated monitoring by lenders. ${ }^{1}$ On the one hand, Diamond (1984) has argued that information gathering may be best delegated to intermediaries to avoid duplicating efforts. On the other hand, others have emphasized the importance of decentralized market trading to support information collection (see, e.g., Holmström and Tirole (1993)). Both approaches capture certainly an important, but ultimately static, difference between different institutional settings.

This paper investigates the consequences of different governance structures on the diffusion of information. We treat the allocation of investors' influence on the firm as exogenously determined. To focus on the institutional structure, we define a firm as debt or equity dominated depending on which investor is dominant in terms of governance, not on the amount of capital supplied.

It is a common perception that bank-dominated firms are more opaque (see e.g., Bhattacharya and Chiesa (1995)). ${ }^{2}$ However, even for firms with little recourse to the public capital market, public information matters since it has strategic effects in a context of imperfect competition (Bhattacharya and Ritter (1982), Gertner, Gibbons, and Scharfstein (1988), and Admati and Pfleiderer (2000)). Therefore, it is important to understand the incentives not only of firms, but also of investors to achieve transparency.

It is not always obvious how firms can credibly disclose private information, since ex post they may prefer to hide unfavorable news. This paper argues therefore that a credible mechanism for the commitment to disclose must be set up in advance, and shows that this choice depends on the preferences of the dominant investor. Specifically, we endogenize the corporate decision to encourage an independent (and thus reliable) process of information dissemination via information gathering and trading of corporate securities by active investors. For instance, ex post transparency may be ensured by an ex ante decision to list (or cross-list) on a market with tight disclosure or active investors.

Most of the early literature on disclosure focuses on the incentive to reveal once a firm has acquired some private information (Stoughton, Wong, and Zechner (2001), Yosha (1995), and Gertner, Gibbons, and Scharfstein (1988)). In contrast, we study the long-term transparency choice, a structural decision before private information is known. We argue that companies are transparent not because of their direct disclosures (which may be ex post unreliable), ${ }^{3}$ but because

\footnotetext{
${ }^{1}$ Arguably, a limitation of the theoretical literature has been its emphasis on normative modeling. A more recent approach studies the political foundations of governance structure (Pagano and Volpin (2000), Perotti and von Thadden (2002)).

${ }^{2}$ For recent evidence of greater opaqueness of banks' assets, see Flannery, Kwan, and Nimalendran (1997).

${ }^{3}$ The incentives to disclose once a firm has acquired some private information are well understood. Firms with good news prefer more or less disclosure depending on the nature of their private information. When it concerns their own strength, firms with good news prefer disclosure. When news concerns the profitability of the market, and competitors may choose to enter, firms with better news
} 
they have put in place structures that allow market participants to gather information and to communicate this information indirectly via market prices. Yet, dominant investors can affect the overall accessibility of corporate information by influencing the cost of acquiring information about the firm.

In our model, companies engage in product market competition after endogenous information revelation via market trading. Since under imperfect competition more opaque firms will exhibit less variability in profits relative to more transparent firms, lenders prefer less transparency.

The economic intuition is as follows. Less transparent firms reveal less to competitors on their competitive strength; thus, ex post they may create either a strategic advantage or disadvantage. When firms act on the basis of less information, their expectation of competitors' output is either too high or too low. This hurts firms that are strong, as it leads competitors to be more aggressive, but it protects weak firms, which can better protect their market share and profitability. As a result, under lack of transparency expected profits are lower, but the volatility of profits and output are lower as well. ${ }^{4}$

Reduced volatility (and in particular the higher profitability in the lower states) increases the return to holders of fixed claims on the firm. This implies that there is a natural preference by lenders for less ex post information dissemination, as they do not gain from higher profits but suffer from higher risk (Jensen and Meckling (1976)).

We show that lender-dominated firms will discourage informative prices, as this would endogenously undermine the value of their claims. In contrast, firms dominated by shareholders encourage greater informativeness of prices, as information dissemination on average increases profitability as well as risk. Competition among firms with different dominant investors does not alter their transparency choice, although a lender's claim enjoys less protection from less public information if its borrower faces a transparent competitor.

There are of course other reasons for banks to wish to limit information diffusion. A natural example arises when lenders have superior information on their clients' credit quality, and are therefore able to charge high information rents (Rajan (1992)). Similar incentives exist also in the case of firms controlled by large shareholders who wish to maintain opaque operations in order to capture some private benefits of control.

Our market microstructure model of information gathering allows us to study the ability to sustain a chosen degree of transparency as external circumstances evolve. An interesting result of the analysis is that there may be interactive effects of information acquisition, leading to multiple equilibria. In particular, we show that information revelation in two markets can be strategically complementary. If this is the case, investors have an incentive to acquire information on one firm only if other investors choose to acquire information on its competitors. As far as we know, this is the first paper to investigate complementarities in information

$\overline{\text { prefer less disclosure (and thus private, bilateral financing, as in Yosha (1995), or Gertner, Gibbons, }}$ and Scharfstein (1988)).

${ }^{4}$ These results are quite robust and hold for the case of Cournot as well as Bertrand competition regardless of whether products are strategic complements or substitutes. For an excellent survey of this general result, see Kühn and Vives (1994). 
generation on competing firms. Here the information revealed by the stock market affects product market competition, thus affecting the return to gather information on competitor firms.

A remarkable implication of this effect is that the ability of dominant investors to limit information dissemination may be undermined by choices made by other firms. A switch of competitor firms toward shareholder value (i.e., to equity control), may have a strong impact on the whole system, because of the complementarity in information production. In some cases, once a firm becomes transparent, informed trading could become profitable also for its bank-controlled competitor. Hence, an exogenous policy change of one group of firms affects the transparency of all firms in equilibrium.

In addition, changing circumstances on the capital market may have the same self-reinforcing effect. For instance, changes in liquidity on the security markets increase the return to information gathering and may lead to more information dissemination, even if the dominant investors seek to limit transparency. This will have an impact on product market competition, the return to gathering information on competing firms, and may thus increase the degree of transparency for other firms as well.

If increasing financial integration leads to greater information revelation through a higher return to information gathering, lenders will less actively discourage the acquisition of information by investors. Moreover, the increasing competition resulting from the greater informativeness of prices tends to raise the riskiness of their claims. Ultimately, this process may reduce the attractiveness of corporate control by banks, and encourage a progressive withdrawal of their influence. In particular, the increase in the riskiness of corporate profits may increase the role of equity, given its comparative advantage in absorbing exogenous risk.

The paper offers also some indication on the effect of an increase in the degree of competition on the product market on transparency. The effect on the evolution of transparency depends very much on the nature of the change in competition. If competition increases in the sense that the products become closer substitutes, the fall in overall profit margins would reduce price variability and thus the incentive to gather information. Of course, information costs may also be reduced by increasing integration and competition. On the other hand, if the increase in competition arises from entry by new firms with more transparent choices, such as firms from other countries, then the result is opposite: complementarity in information gathering will lead to greater transparency for other firms as well, potentially creating a domino effect for the whole industry. A final consideration is that the effect of greater transparency tends to enhance the intensity of product market competition and create a greater wedge between the strong and weaker firms than under more opaque capital markets.

We believe that such results can describe the impact of financial integration in many markets traditionally dominated by banks, such as in continental Europe or in Japan. Entry of new investors and new competitors has put pressure on companies to adopt a more open form of communication with investors. This is widely interpreted as leading to an increasing convergence in financial systems toward an Anglo-Saxon, market-oriented financial system. We thus argue that a cause for 
this change may be the changes in trading intensity and liquidity brought about by the inflow of stock market capital into European and Japanese markets. We then show that due to the informational complementarity, any change in investor activity toward more information acquisition may produce a self-reinforcing movement toward industry-wide information revelation.

While there has been to date little specific empirical analysis, there is some evidence that Japanese companies with influential main banks tend to be less profitable than more independent companies (Caves and Uekusa (1976), Weinstein and Yafeh (1998)). More specifically, these firms appear to have less variability in profitability and grow comparatively less than independent companies (Nakatani (1984)). They also tend to be less liquidity constrained (Hoshi, Kashyap, and Scharfstein (1991)), which is consistent with the model's suggestion that production is more supported in less profitable states under bank funding. All these facts are consistent with our results that less transparent firms competing with more transparent rivals ought to have lower average output and profits and less volatile earnings.

The remainder of this paper is organized as follows. Section II sets out the model. In Sections III-V, we analyze in turn product market competition, financial market activity, and investor choices to solve the model. At the end of Section $\mathrm{V}$, we single out the more interesting comparative statics concerning changes in corporate governance. Section VI concludes. Several lengthy formulas and their derivations are contained in the appendix that is available from the authors or the JFQA Web site (www.jfqa.org).

\section{The Model}

\section{A. Timing and Product Market Interaction}

The model is a dynamic game with five stages. In stage 1, the dominant investors in each firm determine the degree of ex ante transparency of the firm. In stage 2, firms receive some private information about their own quality (which we often refer to as their type). In stage 3, some agents in the stock market can choose to become informed about firm quality at some cost. In stage 4, there is trading in the firms' stocks, which may or may not reveal information. Finally, in stage 5, the two firms, after observing stock market prices, compete in the product market. Then customers make their purchase, and profits are realized and distributed to investors.

We consider two firms who compete in the product market. The firms produce differentiated products and act as Cournot competitors. Firms have either a high or a low quality product, which affects the relative attractiveness of their own product vis-à-vis their competitor's. Quality is described by a parameter $\theta_{i}$ which can take two values. When the product is of high quality, $\theta_{i}=\theta_{H}$, while $\theta_{i}=\theta_{L}$ otherwise, with $\theta_{H}>\theta_{L}$. Product quality is uncertain. Ex ante, either firm has a prior probability $q$ of having a high quality product. The probability of high quality is common to both firms and commonly known. Once output is realized, customers base their purchase on actual quality. 
The inverse demand function faced by firm $i$ is given by

$$
P_{i}=\theta_{i}-Q_{i}-\gamma Q_{j}
$$

where $i=1,2, j \neq i$, and $-1 \leq \gamma \leq 1$. $\gamma$ can be interpreted as the degree of substitutability between the firms' products and describes the intensity of competition in the market. If $\gamma>0$, the two goods are strategic substitutes under Cournot competition. If $\gamma<0$, the goods are strategic complements. ${ }^{5}$ To simplify the exposition, we will concentrate on the case $\gamma \geq 0$. All our main results hold, with minor changes to some formulas, for arbitrary $\gamma$.

To focus on the impact of transparency on competition, we assume that productivity is constant across firms and that marginal costs for each firm are constant and normalized to zero. We assume throughout that the production decision of the firm is taken by managers who maximize profits, i.e., investors do not influence $Q_{i}$ directly. This is in contrast to Brander and Lewis (1986), who analyze the impact of capital structure on product market competition. They show that if the firm has risky debt, equity investors have an incentive to boost output to take advantage of limited liability. Since this effect is not well documented empirically, we choose to work under the assumption of profit maximization. ${ }^{6}$

\section{B. Capital Structure, Influence, and Information Dissemination}

Each firm has a capital structure consisting of debt and equity. To avoid the trivial cases of non-transparency for privately held firms, we assume that the firms' equity is publicly traded. The level of debt financing, given by $D_{i}$, and investor dominance (or influence) are taken to be exogenous. ${ }^{7}$ In this model, investor dominance is not contingent on the level or seniority of leverage. In fact, we consider situations in which dominance arises from legal characteristics of the financial system or the organizational structure of the firm. ${ }^{8}$ We assume that either shareholders or lenders have a dominant influence.

We define influence here as the capacity to determine the ex ante transparency policy of a firm. This is a long-term choice that takes place before firms receive private information, and affects the cost and incentive for ex post information acquisition by investors. ${ }^{9}$ A firm may choose a policy of transparency either by maintaining a broad ex ante disclosure policy, facilitating access to management for analysts and researchers, encouraging secondary trading in the firm's stock, or listing on stock exchanges with stringent disclosure requirements. Given

\footnotetext{
${ }^{5}$ This specification of demand is standard and can be derived from quadratic preferences of a representative consumer (see, e.g., Singh and Vives (1985)).

${ }^{6}$ For theoretical work on the general problem see, e.g., Maksimovic (1988), Bolton and Scharfstein (1990), and Showalter (1995); for contrary empirical evidence see Chevalier (1995).

${ }^{7}$ In related work (Perotti and von Thadden (2001)), we endogenize both dominance and capital structure. For the present purpose, where we analyze the implications of this structure, we can ignore that analysis.

${ }^{8}$ The German Depotstimmrecht (delegated voting right) is an example of a non-transferable source of voting rights that does not stem from share ownership. With this instrument, German banks vote the shares deposited with them by their clients at a firm's general assembly. The amount of such votes varies, but can reach 90\% (see Baums (1996))

${ }^{9}$ This applies, e.g., to European firms deciding to list on the NYSE. Another example is the decision to switch from the British Unlisted Securities Market to the Official List of the LSE.
} 
the long-term, strategic nature of the transparency decision, it is not possible to reveal information credibly for a non-transparent firm after private information is obtained. Of course, there will be in general an ex post incentive to reveal information if it is good, and we assume (realistically) that there is no credible way to communicate ex post only favorable information.

We assume that the governance rights enjoyed by the dominant investor are neither contractible nor transferrable. Thus, financial claims cannot be rearranged contingent on the information.

The firm's transparency choice determines how easy it is for investors to gather information about the firm's quality, $\theta_{i}$. We simplify the problem of transparency and information collection in several ways to keep the problem tractable. First, we assume that a firm can be either transparent $(T)$ or opaque $(O)$, and that this choice comes at no cost. Second, concerning information collection, we assume that each firm has (exactly) one potentially informed investor, who compares the cost of information acquisition with the expected gain from informed trading. If this investor chooses to become informed, she learns the firm's $\theta_{i}$; if this investor remains uninformed, no investor knows $\theta_{i}{ }^{10}$ Third, the firm's transparency determines the fixed cost of learning the firm's type for this market investor. We assume that it costs $K$ to learn the $\theta_{i}$ of an opaque firm and zero to learn that of a transparent firm.

This structure (which is fairly standard) implies that a transparent firm will have informed trading of its stock if only the gains from informed trading are positive (which they are in our model). This does not imply, however, that the firm's quality will always be revealed to the market. In fact, if the informed investor manages to hide her trades behind uninformed trading, her information will only be revealed imperfectly, if at all. Hence, in our model, transparency facilitates information revelation but does not guarantee it.

For the stock market interaction, we employ the simplest possible market microstructure model with profitable informed trading. ${ }^{11}$ We assume that in each market, in addition to the informed investor, there is a set of liquidity traders who, as an aggregate, trade a random amount $+\lambda$ or $-\lambda$ with equal probability $1 / 2$. Prices are set by a competitive market maker at the expected future realization of the stock value conditional on the total order flow. When setting the price in one market, the market maker observes the price realized in the other market. ${ }^{12}$

\section{Product Market Competition}

We analyze the game by solving for subgame perfect equilibria using backward induction. We first examine the impact of more or less public information on product market interaction. We then turn to the incentives for information acquisition in the stock market (Section IV), given the firms' transparency choices, and finally (in Section V) analyze the firms' transparency choices.

\footnotetext{
${ }^{10}$ By assuming just one potentially informed investor, we avoid the problem of information aggregation, which is only tangential to our problem here.

${ }^{11}$ See, e.g., Biais, Foucault, and Hillion ((1997), ch. 3) for a discussion.

${ }^{12}$ This seems to be the more realistic assumption. Our results also hold with little change of the analysis for the case when stock prices do not reflect new information from the competing firm's stock.
} 
There can be only two outcomes concerning the public availability of information about either firm's $\theta$ : either it becomes common information-this happens when an informed investor is present and her trading reveals $\theta$ completelyor it remains private-this happens when there is no informed investor, or the informed investor hides her trading perfectly behind liquidity trading. ${ }^{13}$ Therefore, we have two possible informational states for each firm: $R$ (if its type $\theta$ has been revealed) or $P$ (if its $\theta$ is still private information). In total, this yields four informational structures for market interaction.

\section{A. Competition under Complete Information}

We first consider competition under complete information, defined as a situation in which the information on each firm's $\theta$ is revealed (superscript $R R$ ).

We assume throughout the paper that firms produce a positive level of output, i.e., that there is no exit. This requires assuming that demand even for a low quality product is sufficiently strong. Formally,

$$
\theta_{L} \geq \theta_{H}-\theta_{L}
$$

Both firms simultaneously choose their quantities $Q_{i}$ to maximize profits, taking the other's choice as given. Hence, firm $i$ chooses $Q_{i}$ as to $\max _{Q_{i}}\left(\theta_{i}-Q_{i}-\right.$ $\left.\gamma Q_{j}\right) Q_{i}$

Firm $i$ 's behavior will depend on its own $\theta$ and that of its competitor. We therefore have four different possible states, $i j=H H, H L, L H, L L$, for the interaction. It is straightforward to calculate the unique, symmetric Nash equilibrium $\left(Q_{H L}^{R R}, Q_{H H}^{R R}, Q_{L L}^{R R}, Q_{L H}^{R R}\right)$, where the superscript $R R$ denotes the fact that both firms' $\theta$ s have been revealed, and $Q_{i j}^{R R}$ denotes a firm's equilibrium action if it has quality $\theta_{i}$ and its competitor quality $\theta_{j}{ }^{14}$

The ordering of the corresponding four profit levels is intuitive. In fact, we have

$$
\pi_{H L}^{R R}>\pi_{H H}^{R R}>B \pi_{L L}^{R R}>\pi_{L H}^{R R},
$$

where $L H$ is the worst possible state for firm $i$ and the firm makes lower profits than in state $L L$, the second worst state, etc. ${ }^{15}$

The analysis of this standard form of market interaction is simple. The effect of complete information is to produce some implicit coordination on output decisions, as each firm conditions its production on the actual strength of its competitor's demand and thus on the competitor's ability to expand beyond its own market.

\footnotetext{
${ }^{13}$ This last feature is due to the assumption that liquidity traders buy and sell with the same probability. If those probabilities differed, information would be revealed partially in the case of a zero aggregate order flow.

${ }^{14}$ The derivations are contained in a technical appendix available from the authors or on the JFQA Web site (www.jfqa.org).

${ }^{15}$ If $\gamma<0$, i.e., if the goods are strategic complements, we have $\pi_{H H}^{R R}>\pi_{H L}^{R R}>\pi_{L H}^{R R}>\pi_{L L}^{R R}$ : in $L L$, the worst possible state for firm $i$, it produces less than in state $L H$, the second worst state, etc.
} 


\section{B. Competition under Symmetrically Incomplete Information}

We now consider the case of competition when there is no public information about any firm's quality available. We shall index all variables by $P P$, as all the $\theta \mathrm{s}$ are private information.

Now each firm makes its output decision without knowing its competitor's quality $\theta_{j}$. In this case, each firm will choose output as a function only of its own $\theta_{i}$ and its expectation of the competitor's quality $\theta_{j}$, and therefore chooses $Q_{i}$ to maximize

$$
E_{\theta_{j}} P_{i} Q_{i}=\left\{\begin{array}{c}
\left(\theta_{i}-Q_{i}-\gamma q Q_{H}^{P P}-\gamma(1-q) Q_{L}^{P P}\right) Q_{i} \\
\quad \text { if } Q_{i} \leq \theta_{i}-\gamma Q_{H}^{P P} \\
(1-q)\left(\theta_{i}-Q_{i}-\gamma Q_{L}^{P P}\right) Q_{i} \\
\quad \text { if } \theta_{i}-\gamma Q_{H}^{P P} \leq Q_{i} \leq \theta_{i}-\gamma Q_{L}^{P P} \\
0 \quad \\
\quad \text { if } Q_{i} \geq \theta_{i}-\gamma Q_{L}^{P P}
\end{array}\right.
$$

where $Q_{i}^{P P}$ denotes a firm's equilibrium action when it has quality $\theta_{i}$.

It is readily verified that the game again has a unique symmetric (Bayesian) Nash equilibrium, $\left(Q_{L}^{P P}, Q_{H}^{P P}\right)$, given in the appendix. As in the case of symmetric complete information, it is easy to show that the profit levels in the four different states are ordered as intuition suggests,

$$
\pi_{H L}^{P P}>\pi_{H H}^{P P}>\pi_{L L}^{P P}>\pi_{L H}^{P P}
$$

\section{Competition under Asymmetric Information}

The last case to consider is the asymmetric case, in which the type of one firm, say firm 1, is unknown to the market, whereas the other's type is known. Firm 1, when making its output decision, knows the state of firm 2, but firm 2 does not know $\theta_{1}$. In this case, firm 1 will choose output as a function of $\theta_{1}$ and $\theta_{2}$ and therefore produce as to $\max _{Q}\left(\theta_{1}-Q-\gamma Q_{2}\left(\theta_{2}\right)\right) Q$, where $Q$ depends on $\theta_{1}$ and $\theta_{2}$. Firm 2, on the other hand, seeks to maximize

$$
E_{\theta_{1}} P_{2} Q_{2}=\left\{\begin{array}{l}
\left(\theta_{2}-Q_{2}-\gamma q Q_{1}\left(\theta_{H}, \theta_{2}\right)-\gamma(1-q) Q_{1}\left(\theta_{L}, \theta_{2}\right)\right) Q_{2} \\
\quad \text { if } Q_{2} \leq \theta_{2}-\gamma Q_{1}\left(\theta_{H}, \theta_{2}\right) \\
(1-q)\left(\theta_{2}-Q_{2}-\gamma Q_{1}\left(\theta_{L}, \theta_{2}\right)\right) Q_{2} \\
\quad \text { if } \theta_{2}-\gamma Q_{1}\left(\theta_{H}, \theta_{2}\right) \leq Q_{2} \leq \theta_{2}-\gamma Q_{1}\left(\theta_{L}, \theta_{2}\right) \\
0 \quad \\
\quad \text { if } Q_{2} \geq \theta_{2}-\gamma Q_{1}\left(\theta_{L}, \theta_{2}\right),
\end{array}\right.
$$

where $Q_{2}$ depends on $\theta_{2}$ and firm 2's expectation over $\theta_{1}$.

It is straightforward (if lengthy) to show that the game again has a unique (Bayesian) Nash equilibrium $\left(Q_{H}^{R P}, Q_{L}^{R P}, Q_{H L}^{R P}, Q_{H H}^{R P}, Q_{L L}^{P R}, Q_{L H}^{P R}\right)$, which we spell out in the appendix. Here, $Q_{i}^{R P}$ is the equilibrium quantity produced by the firm whose $\theta$ is known (and which cannot condition on the other firm's quality), and 
$Q_{i j}^{P R}$ is the quantity produced by the firm with private information about its type (which faces a competitor with a publicly known quality) when its own quality is $i$ and that of its competitor $j$. The corresponding eight profit levels (for each state and each firm) are given in the appendix.

Again, it can easily be verified that equilibrium quantities and profits are ordered as in the two equilibria under symmetric information. For example, the profits of a transparent firm facing an opaque firm are highest when the firm has high quality and the competitor low quality, second highest when both have high quality, third highest when both have low quality, and lowest when the firm has low and its competitor high quality.

To understand the costs and benefits of private information in this context, it is useful to compare the profit levels of firm $i$ in the case where both firms' type is public information $\left(\pi^{R R}\right)$ with those where firm $j$ 's type is revealed but firm $i$ 's is not $\left(\pi^{P R}\right)$. Direct inspection shows that profits are ordered state by state. Profits under full information, $\pi^{R R}$, are, in fact, a median-preserving spread of profits under unilateral information, $\pi^{P R}$, in the sense that $\pi^{R R}$ is statewise lower than $\pi^{P R}$ in the two unfavorable states $(L L, L H)$ and statewise higher in the two favorable states $(H H, H L)$. Hence, expected profitability is always higher for the $R$-firm than for the $P$-firm in the strong quality state, and vice versa in the weak quality state. The same comparison holds between $\pi^{P P}$ and $\pi^{R P}$, i.e., if one firm's type is private information. This fact reflects a general result from the industrial organization literature (see, e.g., Kühn and Vives (1994) for an excellent survey) and is at the heart of our argument in this paper. It is therefore useful to discuss its underlying rationale.

The main difference in strategic interaction between the case where a firm's type is revealed and the case where it is not is that the $R$-firm's competitor can react more precisely to the situation on the product market, which makes the intercept of its residual demand more volatile (Fried (1984), Li (1985)). Hence, when in the state of high demand, a firm whose quality is public information $(R)$ can produce more aggressively than if it were not public, because the firm knows that its competitor knows its strength, and will thus restrain its output. In addition, if the competitor's quality is not known, the $R$-firm does not restrain its output when its competitor is strong, since it does not know it. The analogous argument applies for the low quality state. Hence, having one's own type known confers an important strategic advantage (the advantage of forcing the other to restrain itself when one is strong, i.e., when the gains from aggressiveness are highest), even if the competitor's type is private information.

Lack of information can therefore be seen as a device to prevent coordination by competitors. This lack of coordination due to lack of information makes profits higher on average for weaker firms and lower for stronger firms. From an ex ante perspective, the reduced profitability in high quality states, when marginal profitability is highest, is greater than the profit gain in low quality states. Hence, lack of information reduces both expected profits and their variance.

We summarize our findings in the following proposition, whose proof is completed in the appendix. We note in passing that what is important for the analysis is the result about the variance of profits, not their mean. 
Proposition 1. Whatever the information available about the other firm, the mean and the variance of a firm's profits are higher when its quality is public than when it is private information.

\section{Information and Trading in the Stock Market}

\section{A. Trading}

In the last but one stage of the game (the stock market trading stage), one investor may be informed about a firm's $\theta_{i}$; if so, she interacts with uninformed liquidity traders through competitive market makers. As mentioned earlier, we assume that all agents in the market observe the equilibrium stock price of all firms.

Suppose first that there is an informed investor in the market for firm 1's stock. The market maker observes the total order flow. Given that liquidity trading is either $+\lambda$ or $-\lambda$, any trading by the informed investor that is different from $\pm \lambda$ leads to her information being revealed and her trading profits being zero. It is easy to see that she maximizes trading profits by trading $-\lambda$ (short selling) if $\theta_{1}=\theta_{L}$ and $+\lambda$ (buying) if $\theta_{1}=\theta_{H}$.

Whatever information is publicly available about firm 2 , there are three possible outcomes for firm 1's stock. The first is that liquidity traders buy and that $\theta_{1}=\theta_{H}$, which occurs with probability $1 / 2 q$. In this case, the aggregate order flow is $+2 \lambda$ and $\theta_{1}$ is fully revealed. In accordance with the previous section, we denote the full revelation outcome by $R$. The second outcome, which happens with probability $1 / 2(1-q)$, is that liquidity traders and the informed investor sell, so that aggregate order flow is $-2 \lambda$ and $\theta_{1}$ again is fully revealed. In the last case, informed trading just offsets liquidity trading and the aggregate order flow is 0 . This case happens with probability $1 / 2$, and since no information about $\theta_{1}$ is revealed, it is denoted by $P$.

In each case, competitive market makers set prices such that they make expected zero profits. In doing so, they take into account the available information about each firm's quality $\left(\theta_{i}\right)$ and the resulting competitive structure of the product market. Define the value of equity in the different contingencies as

$$
e_{i j}^{x y}=\max \left(\pi_{i j}^{x y}-D, 0\right), \quad x, y \in\{P, R\}, \quad i, j \in\{L, H\},
$$

where $D$ is the firm's debt level and $\pi_{i j}^{x y}$ are the firm's profits before debt, as derived in the last section. Here, the firm is of quality $\theta_{i}$, with a competitor of quality $\theta_{j}$, and the availability of information is described by $x \in\{P, R\}$ for the firm and by $y \in\{P, R\}$ for its competitor. Using this notation, the valuation of equity is straightforward.

Suppose first that the competitor's stock price is non-informative. Then the share price of the firm under consideration is equal to

$$
v(2 \lambda)=q e_{H H}^{R P}+(1-q) e_{H L}^{R P},
$$


if the aggregate order flow received by the market maker is $2 \lambda$, and therefore reveals the firm's quality to be $\theta_{H}$. For an aggregate order flow of $-2 \lambda$, the market value is

$$
v(-2 \lambda)=q e_{L H}^{R P}+(1-q) e_{L L}^{R P},
$$

and if the aggregate order flow is zero, hence uninformative, the value is

$$
v(0)=q^{2} e_{H H}^{P P}+q(1-q) e_{H L}^{P P}+q(1-q) e_{L H}^{P P}+(1-q)^{2} e_{L L}^{P P} .
$$

In the first two cases, the informed investor makes zero expected profits on her trades, because her information is fully revealed by the realized order flow. In the last case, she makes profits at the expense of liquidity traders.

If she has good information and the aggregate order flow is uninformative, her expected profits are

$$
\begin{aligned}
G_{H}(0) & =\left(q e_{H H}^{P P}+(1-q) e_{H L}^{P P}-v(0)\right) \lambda . \\
& =(1-q)\left(q\left(e_{H H}^{P P}-e_{L H}^{P P}\right)+(1-q)\left(e_{H L}^{P P}-e_{L L}^{P P}\right)\right) \lambda,
\end{aligned}
$$

and

$$
G_{L}(0)=q\left(q\left(e_{H H}^{P P}-e_{L H}^{P P}\right)+(1-q)\left(e_{H L}^{P P}-e_{L L}^{P P}\right)\right) \lambda,
$$

if her information is negative.

The reasoning is analogous in the case where the competitor's stock price is informative. If aggregate order flows are $2 \lambda$ or $-2 \lambda$, the price is fully informative and an informed trader makes no profits, whereas she makes

$$
G_{H j}(0)=(1-q)\left(e_{H j}^{P R}-e_{L j}^{P R}\right) \lambda,
$$

if the aggregate order flow is uninformative, her information is good, and the competitor is revealed to be of type $\theta_{j}, j \in\{L, H\}$. Correspondingly, if her information is bad, she makes profits of

$$
G_{L j}(0)=q\left(e_{H j}^{P R}-e_{L j}^{P R}\right) \lambda .
$$

Note that the expected return from informed trading is highest when the true state is the least likely state, as this produces a larger price correction; if $q=1 / 2$, the investor is indifferent between receiving good or bad news.

We can now compute the investor's expected profit from information acquisition. Consider first the case where there is no informed investor in the other market, so that the other firm's stock price will not be revealing. With probability $1 / 2$, the investor in firm 1's stock will be able to profit from her information, and expected profits are, by using (6) and (7),

$$
\begin{aligned}
G^{N} & =\frac{1}{2}\left(q G_{H}(0)+(1-q) G_{L}(0)\right) \\
& =q(1-q)\left(q\left(e_{H H}^{P P}-e_{L H}^{P P}\right)+(1-q)\left(e_{H L}^{P P}-e_{L L}^{P P}\right)\right) \lambda,
\end{aligned}
$$

where the superscript $N$ denotes the fact that there are no informed investors in the other market. 
If there is an informed investor in the other market, the other firm's stock price will be informative with probability $1 / 2$, so expected profits for the informed investor in the first market are obtained by averaging over (6), (7), (8), and (9),

$$
\begin{aligned}
G^{I}= & \frac{1}{2} q(1-q)\left(q\left(e_{H H}^{P P}-e_{L H}^{P P}\right)+(1-q)\left(e_{H L}^{P P}-e_{L L}^{P P}\right)\right. \\
& \left.+q\left(e_{H H}^{P R}-e_{L H}^{P R}\right)+(1-q)\left(e_{H L}^{P R}-e_{L L}^{P R}\right)\right) \lambda,
\end{aligned}
$$

where the superscript $I$ denotes the fact that there is an informed investor in the other market.

The following observation is trivial, but will be important for the analysis of the impact of liquidity trading on the decisions of dominant investors.

Remark 1. The expected return from informed trading is increasing in the volume of liquidity trading $\lambda$.

This is a standard result from the literature on market microstructure. However, it acquires some interesting meaning in the context of our model, in which dominant investors may have differential preferences about the informativeness of prices. We return to this issue in Section V.

Interestingly, the profits from informed trading as a function of what happens in the other market cannot be ordered a priori. It may be that $G^{N}<G^{I}$, in which case information acquisition is complementary across markets. In this case, investing in information is more profitable if information is also acquired in the other market than if it is not. Yet, it is also possible that $G^{N}>G^{I}$, in which case information acquisition in the two markets is exclusionary: investing in information is more profitable if no information is acquired in the other market than if there is information in the other market.

The difference in the attractiveness of information gathering can be reinterpreted as the expected difference in the variation of firm profits under $P R$ competition (which obtains if information in the other market becomes public) relative to $P P$ competition (which obtains if the other market is uninformative). Intuitively, informed trading profits depend on the expected price surprise.

The relative attractiveness of information gathering in the two cases depends on the level of debt. As a benchmark, it is useful to consider the extreme case, when debt is riskless.

Remark 2. If debt is completely riskless in all contingencies, i.e., if $e_{i j}^{P y}=\pi_{i j}^{P y}-D$ for all $y \in\{P, R\}$ and $i, j \in\{L, H\}$, then $G^{I}=G^{N}$, i.e., the value of information in one market is completely independent of information in the other.

The proof follows from straightforward computations using the formulae for $\pi_{i j}^{P y}$ in the appendix. Its intuition is that in the case of riskless debt, the average difference between high and low profits is the same whether the information structure in the product market is $P P$ or $P R$.

In the rest of this paper, we will focus on the more intuitive case of informational complementarity among markets, $G^{I}>G^{N}$. The following proposition shows that this case prevails if debt levels are realistic in the sense that the firm goes bankrupt in the bad state and is solvent in the good state. 
Proposition 2. Information acquisition is complementary across markets $\left(G^{I}>\right.$ $G^{N}$ ), if the debt level is such that it can be repaid whenever the firm's quality is private information and is high, but never when the firm's quality is private information and low.

The condition in the proposition states that the firm's debt level $D$ must satisfy $\pi_{L L}^{P y}<D<\pi_{H H}^{P y}$ for $y=P, R$. It does not restrict the debt level with respect to $\pi^{R x}$ (profits when the firm's quality is revealed), hence, it is fairly weak. Furthermore, the restriction is reasonable and realistic: the firm goes bankrupt if it is bad, and remains solvent when it is good.

If one considers the payoffs from informed trading in the two regimes (which reflect the profit surprise under a $P R$ vs. a $P P$ outcome) as a function of the debt level $D$, we know from Remark 2 that $G^{I}=G^{N}$ if debt is riskless $\left(D \leq \pi_{L H}^{P y}\right)$. Proposition 2 shows that $G^{I}>G^{N}$ if debt is sufficiently large. The only case not covered is thus the case of relatively small but risky debt $\left(\pi_{L H}^{P y}<D<\pi_{L L}^{P y}\right)$. In this case, it is indeed possible in some cases that information acquisition is not complementary $\left(G^{I}<G^{N}\right){ }^{16}$

Proof of Proposition 2. We have

$$
\begin{aligned}
G^{I}-G^{N}= & \frac{1}{2} q(1-q)\left(q\left(e_{H H}^{P R}-e_{L H}^{P R}\right)-q\left(e_{H H}^{P P}-e_{L H}^{P P}\right)\right. \\
& \left.+(1-q)\left(e_{H L}^{P R}-e_{L L}^{P R}\right)-(1-q)\left(e_{H L}^{P P}-e_{L L}^{P P}\right)\right) .
\end{aligned}
$$

By assumption, we have $e_{H j}^{P y}=\pi_{H j}^{P y}-D$ and $e_{L j}^{P y}=0$ for all $y \in\{P, R\}$ and $j \in$ $\{L, H\}$. Hence,

$$
G^{I}-G^{N}=\frac{1}{2} q(1-q) q\left(\pi_{H H}^{P R}-\pi_{H H}^{P P}\right)+(1-q)\left(\pi_{H L}^{P R}-\pi_{H L}^{P P}\right)>0
$$

by explicit calculation.

\section{B. Information Collection}

Solving backward, we now determine the outcomes of the information acquisition subgame on the stock market as a function of the firms' ex ante transparency policy.

As described earlier, we denote the choices by the dominant investors in stage 1 by $T$ (transparent) and $O$ (opaque). Remember that information acquisition in a $T$-firm is costless, and in a $O$-firm costs $K>0$. We denote the decision to acquire information about a firm by $I$ (become informed) or $N$ (no information acquisition).

Proposition 3. If $K<G^{I}, G^{N}$, then $(I, I)$ is the only equilibrium in the information collection subgame for all possible $T-O$ combinations.

This case is trivial: the transparency decision has no economic effect, because information collection is cheap in any case. In the sequel, we shall not elaborate further on this case.

\footnotetext{
${ }^{16}$ Generalizing Proposition 2, one can show that $G^{I}>G^{N}$ if the debt level is such that it can be always repaid except in the worst state $L H\left(\pi_{L H}<D<\pi_{L L}\right)$ and $\gamma$ is small enough and $\theta_{H}-\theta_{L}$ large enough.
} 
Proposition 4. If $G^{I}, G^{N}<K$, then for all possible $T-O$ combinations, the unique equilibrium of the information collection subgame has $I$ if the firm is $T$ and $N$ if $O$.

This is an economically more interesting case. A firm that chooses $T$ can be sure that there will be an informed investor, and a firm choosing $O$ can be sure that there will be no informed investor. The reason is, of course, that information collection is so expensive that it will never happen if the firm is opaque.

A third, and most interesting, possibility is that the cost of information gathering falls in the intermediate range. In this case, each firm's share price will reflect any information revealed about the competitor's share price, so there is strategic interaction between the information-gathering decisions of investors. This gives rise to multiple equilibria.

Proposition 5. If $G^{N}<K<G^{I}$, then $(I, I)$ is an equilibrium of the information collection subgame for all possible $T-O$ combinations. In addition, if both firms are opaque $(O, O)$, then $(N, N)$ is also an equilibrium. ${ }^{17}$

The proof of all three propositions follows from comparing the costs and benefits of information acquisition in the four possible transparency combinations at stage 3. To illustrate the logic, we provide here the payoff matrices for the cases $(T, O)$ and $(O, O)$.

If firm 1 is transparent and firm 2 opaque $(T, O)$, the information acquisition game between the two potentially informed investors is given by the following matrix

\begin{tabular}{|c|cc|c|}
\hline & \multicolumn{2}{|c|}{$I$} & \multicolumn{2}{c|}{$N$} \\
\hline$I$ & \multicolumn{2}{|c|}{$G^{I}$} & $G^{N}$ \\
& \multicolumn{2}{|c|}{$G^{I}-K$} & 0 \\
\hline$N$ & 0 & 0 & 0 \\
\hline
\end{tabular}

To understand the payoff matrix, note that if both investors acquire information $(I, I)$, they both make expected returns of $G^{I}$ from informed trading, but that investor 2 has to pay the information cost $K$ associated with the investigation of an opaque firm. If only investor 1 acquires information $(I, N)$, she makes trading profits of $G^{N}$ while investor 2 in his market makes no trading profit and incurs no information costs. Clearly, in this game, $(I, I)$ is the only equilibrium if $G^{N}<K<G^{I}$.

If both firms are opaque $(O, O)$, however, the matrix looks as follows.

\begin{tabular}{|c|c|c|}
\hline & $I$ & $N$ \\
\hline$I$ & $\begin{array}{l}G^{I}-K \\
\quad G^{I}-K\end{array}$ & $G^{N}-K$ \\
\hline$N$ & $\begin{array}{ll}0 & \\
& G^{N}-K\end{array}$ & $\begin{array}{ll}0 \\
0\end{array}$ \\
\hline
\end{tabular}

\footnotetext{
${ }^{17}$ There is also an equilibrium in mixed strategies, where the probability of choosing $I$ equals $\left(K-G^{N}\right) /\left(G^{I}-G^{N}\right)$.
} 
In this case, no information acquisition for both firms $(N, N)$ is also an equilibrium, although the informative equilibrium $(I, I)$ Pareto-dominates the uninformative equilibrium. The reason for this multiplicity is the complementarity of information production: acquiring information individually does not yield enough trading profits to cover the information costs $\left(G^{N}-K<0\right)$, whereas information production in both markets together is profitable $\left(G^{I}-K>0\right)$.

In general, $I$ is a dominant strategy if the firm is transparent $(T)$, whatever the information structure realized in the other market. Corporate transparency makes information acquisition inexpensive, and liquidity traders ensure that it is profitable.

Unlike the case of Proposition 4, Proposition 5 reflects the intermediate case where the transparency decision by the dominant investor has some impact on information acquisition but is not completely decisive. In particular, if both firms are opaque, it is an equilibrium for strategic investors not to acquire information and therefore preserve the firm's opacity. Yet, in equilibrium both investors may also decide to acquire information, because information acquisition is complementary across markets: investing in information about an opaque firm is profitable if and only if information is also acquired in the other market. In this case, investors may coordinate on information gathering, leading potentially to complete revelation, even when firms attempt to remain opaque.

\section{Transparency Choice}

In this section, we investigate the long-term choice of corporate transparency (the first stage of the game). The two dominant investors choose simultaneously, with the objective of maximizing the expected future value of their financial claim. We first focus on the case $G^{I}, G^{N}<K$ presented in Proposition 4, which also offers key insights for the case of intermediate information costs, which we consider in Section V.D below. We have to distinguish between three different possible allocations of power in the two firms: the case where both are controlled by equity interests, where both are controlled by debt interests, and the mixed case.

It is clear that any theory in which debt and equity have different incentives can only apply to debt levels that are not excessive, otherwise debt would become the residual claimant in all states. In line with the assumption in Section IV.A that $G^{I}>G^{N}$, we therefore assume that in equilibrium equity always receives a positive payoff if the firm is of high quality, i.e., in the states $H H$ and $H L$.

Assumption $A$. $D_{1}, D_{2} \leq \pi_{H H}^{x y}$ for all four possible information structures $x y=\{R R$, $R P, P R, P P\} .{ }^{18}$

\section{A. All Equity Control}

We begin by considering the case in which equity holders exert dominant influence in both firms. Hence, in both firms, the choice of transparency is made such as to maximize

\footnotetext{
${ }^{18}$ Clearly, this assumption is the only reasonable one: the firm does not go bankrupt in the good state. It is, in fact, stronger than what we need for our results.
} 


$$
E \max \left(\pi_{i}^{\star}\left(\theta_{1}, \theta_{2}\right)-D_{i}, 0\right)
$$

where $E$ denotes the expectation over $\left(\theta_{1}, \theta_{2}\right)$, and $\pi_{i}^{\star}\left(\theta_{1}, \theta_{2}\right)$ are equilibrium profits in the product market, given product quality and the information available after financial market activity (which will be influenced by the choice of transparency). To understand the costs and benefits of transparency in this context, it is useful to compare the profit levels before debt payments of firm $i$ in the case where both firms' types are revealed $\left(\pi^{R R}\right)$ with those where firm $j$ 's type is revealed but firm $i$ 's is not $\left(\pi^{P R}\right)$. As discussed in Section III, the comparison shows that profits are more variable under fully revealed competition than under competition with asymmetric information: $\pi^{R R}$ is a median-preserving spread of $\pi^{P R}$, in the sense that $\pi^{R R}$ is statewise lower than $\pi^{P R}$ in the unfavorable states $(L L, L H)$ and statewise higher in the favorable states $(H H, H L)$. Figure 1 summarizes the discussion given in Section III.

FIGURE 1

Comparing $\pi^{R R}$ and $\pi^{P R}$

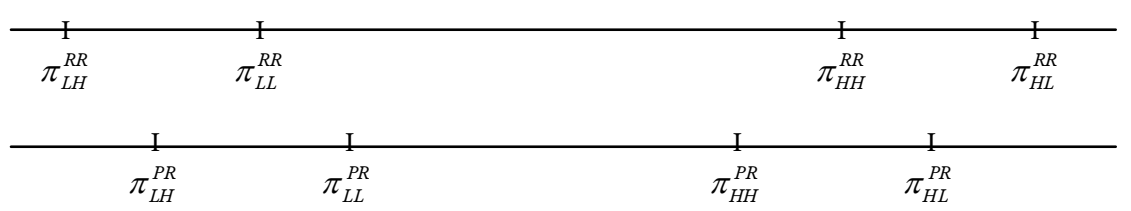

This observation suggests that equity, which cares about the upside of profits, prefers the distribution $\pi^{R R}$ over $\pi^{P R}$. However, investors cannot directly reveal $\theta_{i}$; they can only influence its revelation through increased transparency. As Section IV shows, under transparency, $\theta_{i}$ will be revealed with probability $1 / 2$ and remain private information with probability $1 / 2$. If the firm is opaque, $\theta_{i}$ will not become public for sure. Comparing these two alternatives leads to the following proposition.

Proposition 6. If both firms are controlled by equity interests and if $G^{I}, G^{N}<K$, then both firms are transparent in the unique subgame perfect equilibrium of the game.

Proof. A transparent firm will have its quality revealed in the financial markets with probability $1 / 2$, whereas an opaque firm will keep its quality secret with probability 1 . Therefore, if firm $j$ is transparent, an equity-controlled firm $i$ prefers to be transparent if

$$
\begin{aligned}
\delta\left(D_{i}\right) & \equiv E \max \left(\pi_{i}^{R R}\left(\theta_{1}, \theta_{2}\right)-D_{i}, 0\right)-E \max \left(\pi_{i}^{P R}\left(\theta_{1}, \theta_{2}\right)-D_{i}, 0\right) \\
& \geq 0 .
\end{aligned}
$$

The state-by-state comparison of profit levels given in Figure 1 implies that $\delta\left(D_{i}\right)>0$ for all $D_{i}$ if $\delta(0)>0$. This is because the graph of $\delta$ is (weakly) single 
peaked, which becomes clear when walking backward from $\pi_{H L}^{R R}$ (where $\delta=0$ ) in Figure 2.

FIGURE 2

The Graph of $\delta$

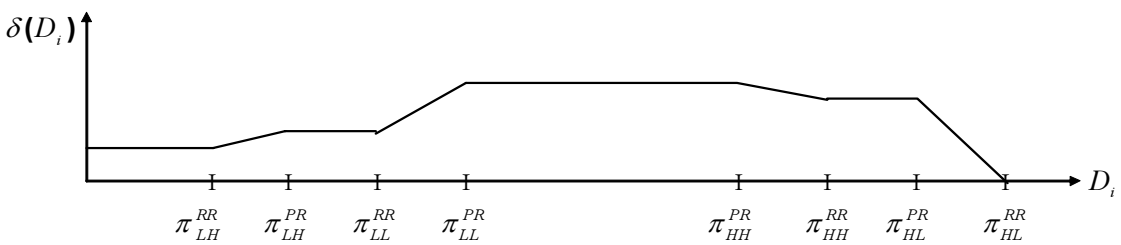

In other words, $\delta$ is positive for all $D_{i}$ if only $E \pi_{i}^{R R}>E \pi_{i}^{P R}$, which has been established in Proposition 1.

This proves that $O T$ and $T O$ cannot be equilibrium transparency structures. To prove uniqueness, we have to compare the transparency structure $O O$ with $T O$. As in Figure 1, it is straightforward to compare $\pi^{P P}$ and $\pi^{R P}$ state by state. Again, profits with revealed quality are a spread of profits with private information about quality as Figure 3 shows.

FIGURE 3

Comparing $\pi^{R P}$ and $\pi^{P P}$

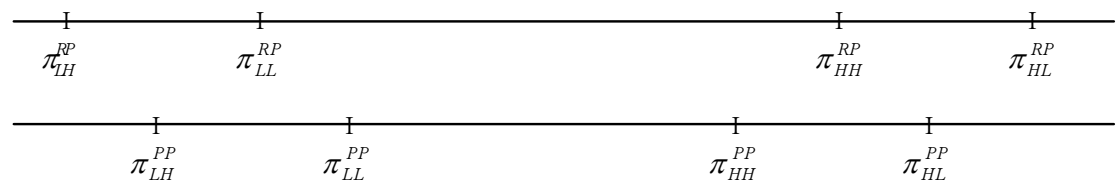

An equity-controlled firm wants to deviate from $O O$ to $T O$ if

$$
\begin{aligned}
\beta\left(D_{i}\right) & \equiv E \max \left(\pi_{i}^{R P}\left(\theta_{1}, \theta_{2}\right)-D_{i}, 0\right)-E \max \left(\pi_{i}^{P P}\left(\theta_{1}, \theta_{2}\right)-D_{i}, 0\right) \\
& >0
\end{aligned}
$$

By the same argument as above, (15) holds for all $D_{i}$ if it holds for $D_{i}=$ 0 . This again has been established in Proposition 1. Hence, $O, O$ cannot be an equilibrium.

As the proof shows, transparency is, in fact, a dominant strategy in the game between equity holders at the first stage (taking the equilibrium strategies in the following stages as given). The effect of complete information is to produce some implicit coordination, as each firm conditions its production on the actual strength 
of its competitor's demand and thus on the competitor's incentive to expand. This implicit coordination is so valuable that an equity-controlled firm unilaterally prefers to become transparent.

\section{B. All Debt Control}

We now turn to the case in which lenders exert the dominant influence in both firms. Hence, in both firms, the choice of transparency is made such as to maximize

$$
E \min \left(\pi_{i}^{\star}\left(\theta_{1}, \theta_{2}\right), D_{i}\right)
$$

Figures 1 and 3 also provide the intuition about costs and benefits of information revelation in this case. Take the situation described in Figure 3. A lender-controlled firm that faces a non-transparent competitor has the choice between the random profits $\pi^{P P}$, if it chooses opaqueness and $1 / 2\left(\pi^{P P}+\pi^{R P}\right)$, if it chooses transparency. ${ }^{19}$ Since the dominant interest now is to protect the downside of profits, lenders will prefer $\pi^{P P}$ (because equity gets the upside of profits, as in Assumption A). If their debt is risky, so that $D_{i}$ is above the lowest possible profit level under $R P$, which is $\pi_{L H}^{R P}$, they will strictly prefer $\pi^{P P}$. To simplify, we focus on the case of symmetric debt levels and impose a minimum level of leverage, to exclude the trivial case of riskless debt.

Assumption B. $D_{1}=D_{2}=D>\max \left(\pi_{L H}^{R P}, \pi_{L H}^{R R}\right)$.

As Assumption A, Assumption B is consistent with (in fact, weaker than) the assumption in Section IV.A that information collection in the two markets is complementary. We can now easily characterize the behavior of dominant lenders.

Proposition 7. Suppose both firms are lender controlled, that $G^{I}, G^{N}<K$, and that $D$ satisfies Assumptions $\mathrm{A}$ and $\mathrm{B}$. Then the game has a unique subgameperfect Nash equilibrium in which both firms are opaque.

Proof. If the competitor is transparent, firm $i$ (strictly) prefers to be opaque if and only if

$$
\eta\left(D_{i}\right) \equiv E \min \left(D_{i}, \pi_{i}^{P R}\left(\theta_{1}, \theta_{2}\right)\right)-E \min \left(D_{i}, \pi_{i}^{R R}\left(\theta_{1}, \theta_{2}\right)\right)>0 .
$$

As in the proof of Proposition 6, it is straightforward to draw the graph of $\eta$. Noting that $\eta\left(\pi_{L H}^{R R}\right)=0$ and $\eta\left(\pi_{H H}^{R R}\right)>0$ by assumption, the graph has the form shown in Figure 4. Figure 4 shows that indeed $\eta\left(D_{i}\right)>0$ for all debt levels permitted by Assumption A. Hence, $O$ is the dominant lender's unique best response to $T$. A similar argument establishes that it is also for $O$.

Proposition 7 provides a converse to Proposition 6: whereas in the case where all equity control firms will be transparent, dominant lenders choose to be opaque, if debt is risky. As in the case of transparency for equity control, opaqueness is in fact a dominant strategy for controlling lenders.

\footnotetext{
${ }^{19}$ Remember that transparency in our model does not mean that the firm's type is revealed for sure. Transparency just means that information acquisition in the financial market is easy, which may or may not lead to the firm's type being revealed.
} 
FIGURE 4

The Graph of $\eta$

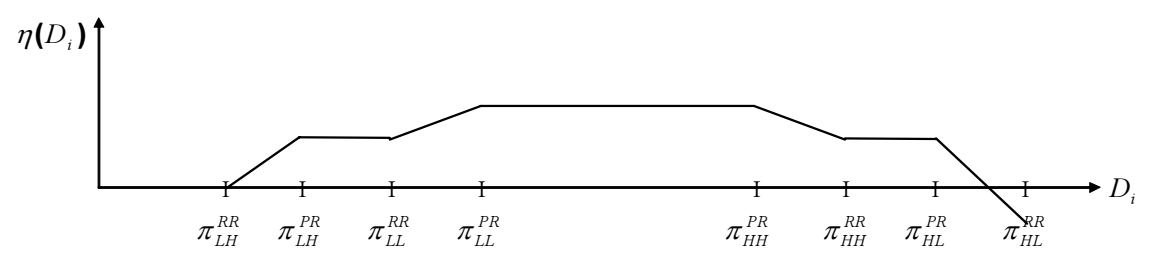

\section{The Mixed Case}

Now we consider the case of competition between two different modes of dominance. Assume that firm 1 is dominated by equity interests, whereas firm 2 is dominated by lender interests. Hence, firm 1's objectives are given by (13) and firm 2's by (16).

Given the results of subsections A and B, the analysis is straightforward. By Proposition 6, firm 1's dominant strategy in the game of transparency choice is $T$. By Proposition 7, firm 2's dominant strategy is $O$.

Proposition 8. Suppose that firm 1 is equity controlled and firm 2 lender controlled, that $G^{I}, G^{N}<K$, and that debt levels satisfy Assumptions A and B. Then the unique subgame-perfect equilibrium has firm 1 being transparent and firm 2 being opaque.

This situation is a combination of those in the preceding two subsections. Equity will always prefer transparency, while the lenders' best response is opaqueness. The reason is as discussed following Proposition 4: information acquisition in the financial market is sufficiently expensive for an opaque firm to remain opaque no matter what the information structure for the other firm. Hence, competition across firms under two different regimes of corporate control will not change their choice of transparency.

\section{Equilibrium in the Case of Intermediate Information Costs}

This last feature changes when information collection costs, $K$, are lower. We now turn to this case, considered in Proposition 5, where $G^{N}<K<G^{I}$. As we know from Proposition 5, the equilibrium continuation at stage 3 of the game may not be unique.

In fact, by Proposition $5(I, I)$ is the unique equilibrium continuation given stage 1 choices $(T, T),(T, O)$, and $(O, T)$. Following $(O, O)$, on the other hand, $(N, N)$ also can arise in equilibrium (as well as a mixed strategy equilibrium).

We know from the proof of Proposition 6 that equity prefers information revelation $(R)$, regardless of the situation of the competitor. Yet, we also know from Proposition 5 that information will be acquired in both markets if only one firm is transparent. Hence, theoretically, equilibria exist in which one equity-controlled firm is transparent and the other opaque (and where the opaqueness does not pre- 
vent the market from becoming informed). These equilibria are asymmetric in the sense that different controlling equity holders choose different actions, one action (opaqueness) being chosen only because the investor knows that it has no impact in equilibrium (due to the complementary nature of information collection). This is artificial. Furthermore, these equilibria are not stable in the sense that if there is the slightest doubt about whether the other firm will be transparent, an equitycontrolled firm will choose transparency at stage 1 regardless of its competitor's choice. In fact, doing so guarantees that investors will collect information on both firms, thereby making it likely that information will be revealed for product market competition. The most reasonable equilibrium in the case of all equity control (the counterpart to Section V.A) is therefore that of both firms being transparent also for intermediate information costs.

A similar reasoning applies in the mixed case (the counterpart of Section V.C). Although there also exist equilibria in which both firms are opaque and information is collected after all because the costs $K$ are sufficiently low, the above argument suggests that the most reasonable equilibrium is the one in which equity-controlled firms are transparent and debt-controlled firms are opaque, but in which information is collected in both markets. In this equilibrium (as in all others in the mixed case), controlling debt holders will be indifferent, because their choice has no impact on financial markets: as the competitor is transparent, the complementary nature of information acquisition will make information acquisition profitable even in an opaque firm. ${ }^{20}$

In the case of debtor control of the two firms, the transparency choice depends on anticipated investor behavior in the financial market, too. If investors acquire information (the case $(I, I)$ in Proposition 5), controlling debt holders will be indifferent. However, if there is the slightest possibility that there is no information collection for opaque firms, then only overall opacity $(O, O)$, is an equilibrium choice.

What is important under intermediate information costs is that debtors have less control over the informativeness of stock prices even if they attempt to hold the firm opaque. It is therefore possible in equilibrium to have market investors profitably collecting information about opaque firms. Anticipating this, dominant debtors may accept letting their firms be transparent.

\section{E. Comparative Statics and the Impact of International Integration}

Our model allows for some interesting comparative statics concerning parameters that may be interpreted to reflect international economic factors and financial integration. In particular, these results may shed light on some recent trends resulting from increased trading, cross-listings, and portfolio integration

\footnotetext{
${ }^{20}$ Formally, the subgame-perfect equilibria outcomes are $(T, T),(T, O)$, and $(O, T)$ for stage 1 (with $(I, I)$ as the unique continuation in stage 3$)$. Also $(O, O)$ is a stage 1 equilibrium outcome, if the stage 3 equilibrium continuation is $(I, I)$. This indifference of controlling debt holders comes from our assumption about information dissemination. In our model, we assume that information about a firm can only be spread if financial markets are actively engaged in collecting and using it. If we changed this assumption and called transparency the simple commitment to truthfully reveal $\theta_{i}$, then debt-controlled firms would strictly prefer opaqueness. The reason why we choose to work with the present model is that it gives an informational role to the market in the stock of transparent firms.
} 
in continental European capital markets, and by increased internationalization of product market competition.

Relevant parameters are the extent of liquidity trading on the stock market, $\lambda$, which can be seen rather naturally as increasing in the diffusion of shareholdings across international investors, the costs of information acquisition, $K$, which reflect at least partially technological and accounting advances, and the degree of product market competition, $\gamma$.

We first start by considering the effect on transparency if market depth (in our model the amount of noise trading, $\lambda$ ) increases. As noted in Remark 1, the effect is that trading profits for informed investors $G^{I}$ and $G^{N}$ will increase. Suppose that the economy is initially in a situation in which these profits are smaller than information costs $K$, (the case in Proposition 4 and Sections V.A-C). In this case, banks can successfully prevent information dissemination to competitors, and they can even do this unilaterally (Section V.C). If $\lambda$ increases until $G^{I}$ exceeds $K$, a restrictive corporate disclosure policy may fail to restrict informativeness. In fact, because of the multiplicity of equilibria in information collection (Proposition 5), financial market activity may become better informed and more informative even though this is not in the interest of the dominant investors. One is therefore tempted to argue that the large influx of international capital into European financial markets since the mid 1990s, the increasing number of European firms cross-listed in the U.S. and in London, the progressive globalization of competition, and the recent shift to greater transparency of many European companies (and some Japanese ones) are related phenomena. The effect will be reinforced if there are external effects of information gathering (or increasing competition) that reduce $K$.

Similarly, we can identify economy-wide consequences of the recent push for shareholder value in Europe. Suppose that information costs are not too high, and that the system is bank controlled with little information revelation. If now there is an entry by a more transparent competitor, or one of the incumbent firms switches to transparency because of changing shareholder pressure, there will be a sweeping impact on the whole system. Because of the complementarity in information production, informed trading will become profitable also for the bank-controlled firms, and markets will become more informative economywide. Hence, an exogenous governance change of one group of firms affects the information dissemination for all firms in equilibrium. With opaque governance structures now having no role to play but to impose system-wide costs $(K)$, it is even conceivable that this would lead to a domino effect among opaque firms in the same industry, all adopting more transparent governance structures.

The effect of an increase in the degree of competition on the product market depends on the form of increased competition. It is straightforward to show from (11) and (10) that $G^{I}$ and $G^{N}$ are decreasing functions of $\gamma$. On the other hand, the opening of international markets tends to increase profit opportunities. Hence, the overall level of corporate profits and their variability, and also the gains from exploiting superior information, may decrease or increase, with an ambiguous impact on transparency. However, there are other countervailing effects of economic integration on the evolution of transparency. First, information costs may also be reduced by increasing competition on the product market. Possibly 
more importantly, increasing competition often manifests itself through entry of foreign firms; to the extent that these firms may be more transparent than local competitors would lead to increased transparency for the whole sector.

\section{Conclusions}

In this paper, we have highlighted the impact of dominant investors on the diffusion of information. We provide an explanation for the observation that lender-dominated firms tend to be more opaque. Besides the low transparency traditionally accompanying debt financing, our explanation is that the informativeness of market information may be deliberately curtailed to mitigate product market competition. In particular, we highlight the vulnerability of this strategic opaqueness to changes in external circumstances.

An interesting result is that the informational advantage of an opaque firm facing a transparent competitor does not translate into an outright competitive advantage. While lack of transparency ensures that a firm is shielded when in a weak competitive position, when the firm is in a strong position it cannot take full advantage of common knowledge of its strength to restrain output by competitors, losing market share precisely when its product is relatively profitable. Hence, the value of transparency depends on whether investors are interested in the upside or the downside of profits.

Our notion of debtor control captures a limited, but probably important part in the institutional setting of corporate governance systems. One qualification, however, is that to exert control, debt holders must act in a concerted manner, which is usually impossible if debt is widely held, and that equity must be relatively weak. This is because, except in bankruptcy, equity has the formal control rights and can, therefore, impose its preferences on debt holders (unless explicitly restricted by covenants). As a consequence, we have the following rough taxonomy to anchor the classification of our theory institutionally. Equity control is present whenever equity is strong. Debt control prevails if equity is weak and there are influential debt holders, such as a main bank. Finally, if equity and debt are both relatively weak (e.g., widely held), we expect management to be in control. In this latter case, it becomes crucial whether managers are interested in the upside or downside of profits. In the earlier literature on managerial discretion (see, e.g., Shleifer and Vishny (1997)), management typically prefers opaqueness. The recent public debate over the lack of transparency and other basic corporate governance issues in corporate America shows that this literature is still highly topical.

In an international context, our notion of debt control is presumably more relevant to Japanese or European than to U.S. companies, where equity or management control seems to be the norm. Thus, on average, our model predicts higher corporate transparency in the U.S. (and perhaps the U.K.) relative to Japan and Europe.

Some interesting applications for the evolution of corporate governance result from examining the effect of parameter changes driven by financial integration. We have shown that opaqueness may be increasingly hard to sustain as trading liquidity rises due to rising global investment flows. More investment 
by uninformed foreign investors increases the profits to informed trading even if the dominant investors attempt to maintain opaqueness. Greater informativeness of prices not only tends to lead to more intense competition and greater average profitability, but also to greater profit variability and riskiness. Greater transparency may also lead to more natural selection among firms. Similar effects will arise with foreign entry by transparent firms. On balance, we conclude that increasing integration and competition may not force the convergence of corporate governance systems (the identity of the dominant investors and their interests may remain unchanged), but that important characteristics of corporate governancesuch as transparency and product market behavior-are likely to converge. Hence, we expect the differences between different systems of corporate governance to become less important.

The Appendix can be found at www.jfqa.org.

\section{References}

Admati, A., and P. Pfleiderer. "Forcing Firms to Talk: Financial Disclosure Regulation and Externalities." Review of Financial Studies, 13 (2000), 479-519.

Baums, T. "Vollmachtstimmrecht der Banken—Ja oder Nein?" Die Aktiengesellschaft, 1 (1996), 11-26.

Bebchuk, L. A., and M. Roe. "A Theory of Path Dependence in Corporate Ownership and Governance." Stanford Law Review, 52 (1999), 775-808.

Bhattacharya, S., and G. Chiesa. "Proprietary Information, Financial Intermediation, and Research Incentives." Journal of Financial Intermediation, 4 (1995), 328-357.

Bhattacharya, S., and J. Ritter. "Innovation and Communication Signalling with Partial Disclosure." Review of Economic Studies, 50 (1982), 331-346.

Biais, B.; T. Foucault; and P. Hillion. "Microstructure des Marchés Financiers." Paris, France: Presses Universitaires de France (1997).

Biais, B., and E. Perotti. "Machiavellian Underpricing." American Economic Review, 92 (2002), 240-258.

Bolton, P., and D. Scharfstein. "A Theory of Predation Based on Agency Problems in Financial Contracting." American Economic Review, 80 (1990), 93-106.

Brander, J., and T. Lewis. "Oligopoly and Financial Structure." American Economic Review, 76 (1986), 956-970.

Caves, R., and M. Uekusa. Industrial Organization in Japan. Washington, DC: The Brookings Institution (1976).

Chevalier, J. "Capital Structure and Product Market Competition: Empirical Evidence from the Supermarket Industry." American Economic Review, 85 (1995), 415-435.

Diamond, D. "Financial Intermediation and Delegated Monitoring." Review of Economic Studies, 51 (1984), 393-444.

Easterbrook, F. H., and D. R. Fischel. The Economic Structure of Corporate Law. Harvard Univ. Press (1991).

Flannery, M.; S. Kwan; and M. Nimalendran. "Market Evidence on the Opaqueness of Banking Firms' Assets.” Mimeo, Univ. of Florida (1997).

Fried, D. "Incentives for Information Production and Disclosure in a Duopolistic Environment." Quarterly Journal of Economics, 99 (1984), 367-381.

Gertner, R.; R. Gibbons; and D. Scharfstein. "Simultaneous Signalling to the Capital and Product Markets." RAND Journal of Economics, 19 (1988), 173-190.

Hansmann, H., and R. Kraakman. "The End of History for Corporate Law." In Are Corporate Governance Systems Converging? J. Gordon and M. Roe, eds. (forthcoming 2003).

Holmström, B., and J. Tirole. "Market Liquidity and Performance Monitoring." Journal of Political Economy, 101 (1993), 678-709.

Hoshi, T.; A. Kashyap; and D. Scharfstein. "Corporate Structure, Liquidity, and Investment: Evidence from Japanese Industrial Groups.” Quarterly Journal of Economics, 106 (1991), 33-60.

Jensen, M., and W. Meckling. "Theory of the Firm: Managerial Behavior, Agency Costs and Ownership Structure.” Journal of Financial Economics, 3 (1976), 305-360. 
Kühn, K.-U., and X. Vives. "Information Exchanges among Firms and Their Impact on Competition." Mimeo, Institut d'Analisi Economica, Barcelona (1994).

La Porta, R.; F. Lopez-de-Silanes; A. Shleifer; and R. Vishny. "Legal Determinants of External Finance." Journal of Finance, 52 (1997), 1131-1150.

. "Law and Finance." Journal of Political Economy, 107 (1998), 1113-1155.

Li, L. "Cournot Oligopoly with Information Sharing." RAND Journal of Economics, 16 (1985), 521536.

Maksimovic, V. "Capital Structure in Repeated Oligopolies." RAND Journal of Economics, 19 (1988), 389-407.

Nakatani, I. "The Role of Financial Corporate Grouping." In Economics Analysis of the Japanese Firm. M. Aoki, eds. New York, NY: North Holland (1984).

Pagano, M., and P. Volpin. "The Political Economy of Corporate Governance." CEPR Discussion Paper, 2682 (2000), CEPR, London.

Perotti, E., and E.-L. von Thadden. "Dominant Investors and Strategic Transparency." Unpubl. Paper, Université de Lausanne (2001).

"The Political Economy of Bank versus Market Dominance." Unpubl. Paper, Université de Lausanne (2002).

Rajan, R. "Insiders and Outsiders: The Choice between Informed and Arm's Length Debt." Journal of Finance, 47 (1992), 1367-1400.

Rajan, R., and L. Zingales. "The Great Reversals: The Politics of Financial Development in the 20th Century." Working Paper, Univ. of Chicago (2001).

Shleifer, A., and R. Vishny. "A Survey of Corporate Governance.” Journal of Finance, 52 (1997), 737-783.

Showalter, D. M. "Oligopoly and Financial Structure: Comment." American Economic Review, 85 (1995), 647-653.

Singh, N., and X. Vives. "Price and Quantity Competition in a Differentiated Duopoly." RAND Journal of Economics, 15 (1985), 546-554.

Stoughton, N.; K. P. Wong; and J. Zechner. "IPOs and Product Quality." Journal of Business, 74 (2001), 375-408.

Weinstein, D. E., and Y. Yafeh. "On the Costs of a Bank-Centered Financial System: Evidence from the Changing Main Bank Relations in Japan." Journal of Finance, 53 (1998), 635-672.

Yosha, O. "Information Disclosure Costs and the Choice of Financing Source." Journal of Financial Intermediation, 4 (1995), 3-20. 